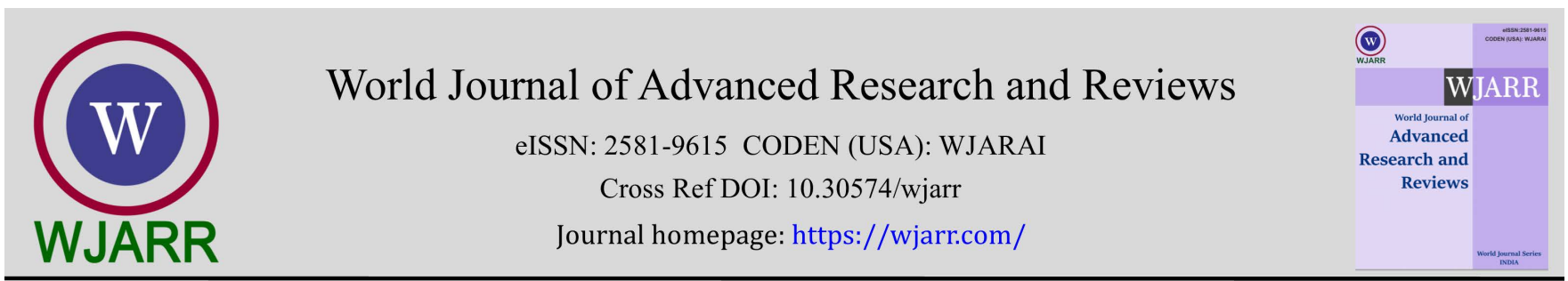

(CASE REPORT)

\title{
Pancreatic duct stones and laser treatment: A case report
}

\author{
Filipa Ribeiro Lucas ${ }^{1,}{ }^{*}$, Soraia Proença e Silva ${ }^{1}$ and João Gigante ${ }^{2}$ \\ ${ }^{1}$ Internal Medicine, Castelo Branco Hospital, Castelo Branco, Portugal. \\ ${ }^{2}$ Clinical Pathology, Prof. Doutor Fernando da Fonseca Hospital, Lisbon, Portugal.
}

World Journal of Advanced Research and Reviews, 2021, 12(03), 001-004

Publication history: Received on 24 October 2021; revised on 01 December 2021; accepted on 03 December 2021

Article DOI: https://doi.org/10.30574/wjarr.2021.12.3.0655

\begin{abstract}
A 62 years-old Caucasian male, who had a consumptive condition associated with recurrent episodes of abdominal pain, was evaluated in a Gastroenterology consultation.

Physical examination was quite innocent and the following imaging exams were performed. A Computed Tomography (CT) showed a thin gallbladder and chronic pancreatitis signs with pancreatic intraductal stones, dominant at tail and body, associated with pancreatic tail atrophy. An abdominal-Magnetic Resonance Imaging (MRI) showed an abnormal pancreatic parenchyma, a mild Wirsung dilatation and an unknown pancreatic head stenosis etiology. Therefore, to clarify the pancreatic stenosis, an echo-endoscopy (EUS) was performed. This exam showed a 10-mmstone associated with a focal narrowing in the head/tail transition.
\end{abstract}

A pancreatoscopy-guided holmium laser using a mini-endoscope inserted into the pancreatic duct successfully broke the impacted stone and cleared the obstruction, without complications. After that, endotherapy with plastic stents was repeatedly done, during the following 6 months.

After endoscopic treatment, the patient recovered quite well, without any symptoms, without pancreatic stenosis and higher quality of life.

Keywords: Chronic pancreatitis; Holmium laser; Pancreatic duct stone; pancreatoscopy

\section{Background}

Pancreatic duct stone formation is a chronic pancreatitis complication that causes recurrent episodes of pain and can be manage endoscopically.

Patients with difficult pancreatic duct stones can be treated with holmium laser, which is a safe and effective treatment. It is a promising method for experienced gastroenterologists and may replace, in a near future external lithotripsy in the management of intraductal stones.

\section{Case Presentation}

We report a case of a 62-year-old male with heavy alcohol consumption referred to a Gastroenterology Consultation with recurrent episodes of diffuse abdominal pain. He has also medical history of chronic pancreatitis; type 2 Diabetes Mellitus with diabetic retinopathy and diabetic foot ulcer; hypertension and Charcot syndrome. He takes sitagliptin plus metformin (50/1000 mg); insulin (20U+22U); amlodipine plus valsartan (5/160 mg); clopidogrel 75 mg; ranitidine

\footnotetext{
${ }^{*}$ Corresponding author: Filipa Ribeiro Lucas

Internal Medicine, Castelo Branco Hospital, Castelo Branco, Portugal.

Copyright (C) 2021 Author(s) retain the copyright of this article. This article is published under the terms of the Creative Commons Attribution Liscense 4.0.
} 
150mg; nebivolol 5mg and aspirin 100mg and he had no known drug allergies. Clinical evaluation was unremarkable, and some imaging exams were performed. A Computed Tomography (CT) demonstrated a thin gallbladder and chronic pancreatitis signs with pancreatic intraductal stones, dominant at tail and body, associated with pancreatic tail atrophy. The Magnetic Resonance Cholangiopancreatography (MRCP) showed an abnormal pancreatic parenchyma, a mild Wirsung dilatation and unknown pancreas duct stenosis at head of pancreas. To clarify the pancreatic stenosis, an echoendoscopy (EUS) illustrated a 10-mm stone associated and a focal narrowing in body/tail transition. Three months after, an ERCP was carry out to introduce a pancreatic stent $(10 \mathrm{Fr}, 12 \mathrm{~cm})$.

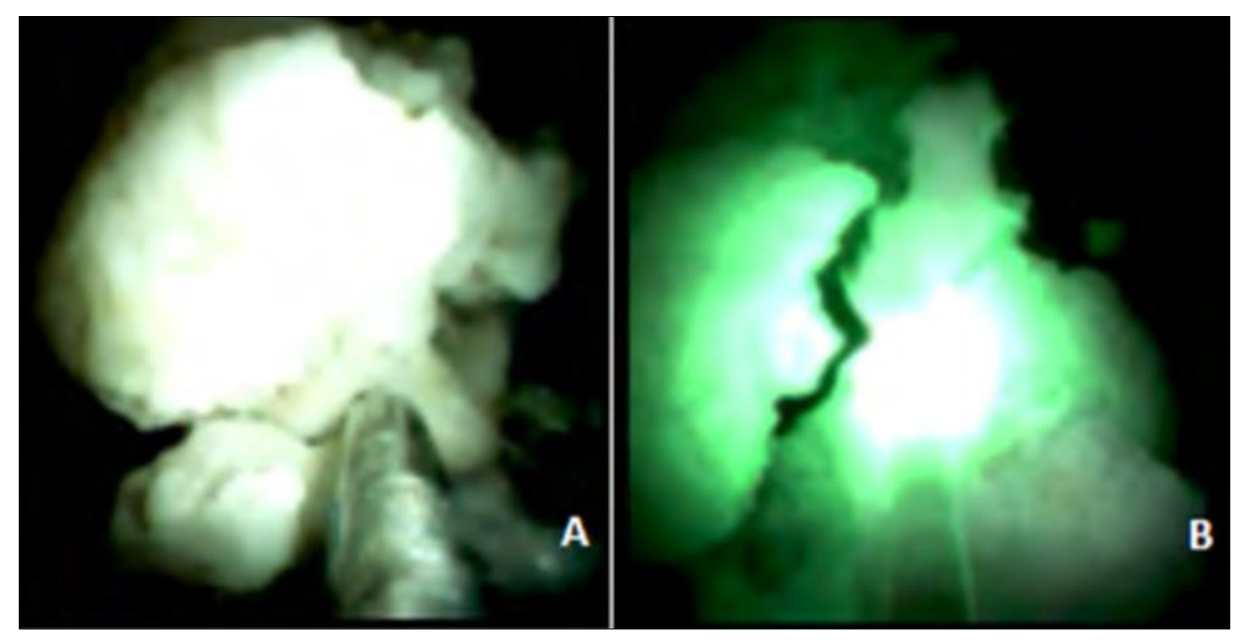

Figure 1 Visualization System (SGDS), using a single-operator four-way deflected 10-Fr Spy-Scope (Boston Scientific, Natick, MA, USA) inserted through the 4.2-mm working channel. A) Impacted pancreatic duct stone (white mass) with a median diameter of $10 \mathrm{~mm}$. B) It showed the mini endoscope inserted into the pancreatic duct (black tube). Laser is bursting the stone, under intermittent saline irrigation. C) We can see the successful impacted stone destruction and a clean channel

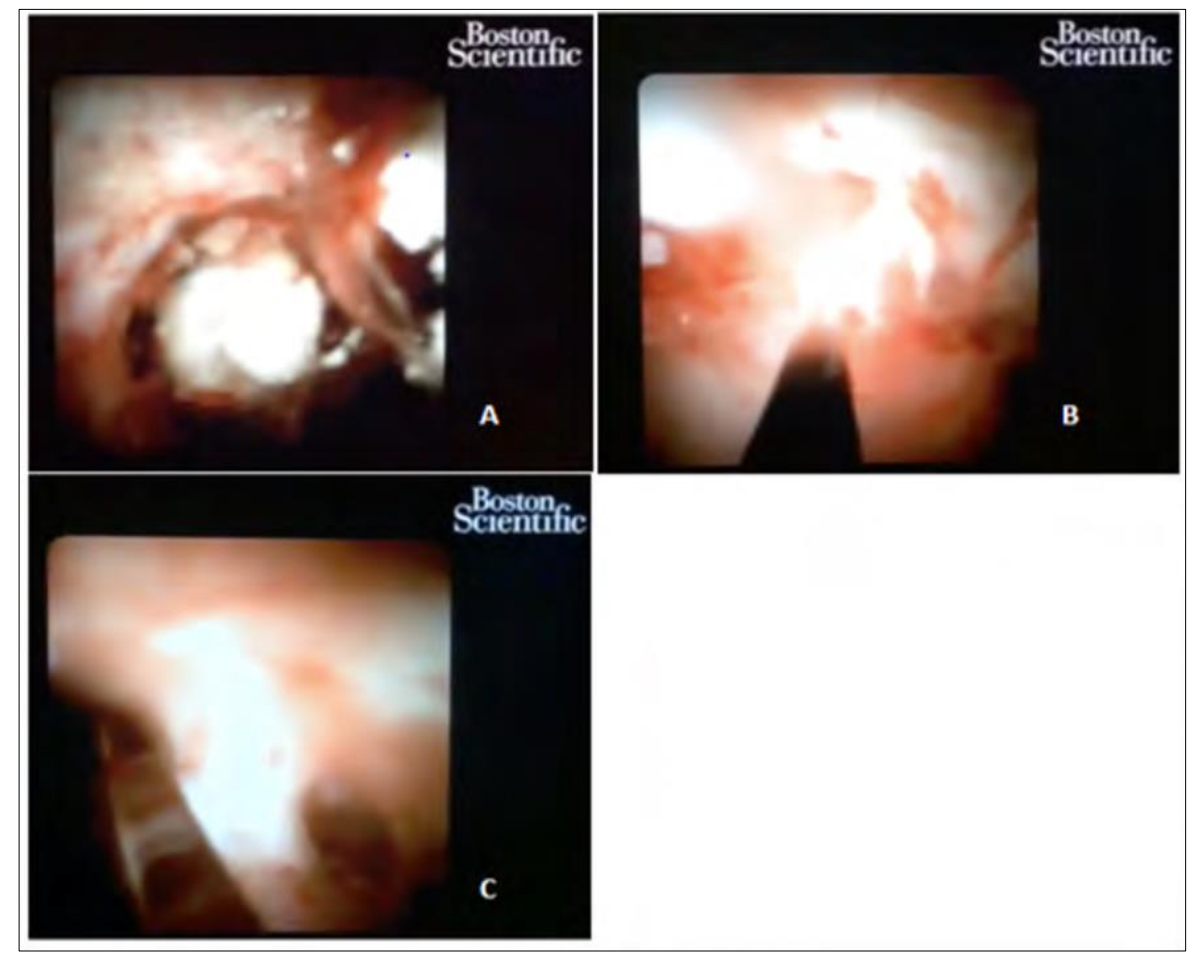

Figure 2 Example of laser lithotripsy performed under direct visualization by use of a pancreatoscope passed through the duodenoscope. (A) It shows the pancreatic duct stone (white mass) and the endoscope (silver tube); (B) It shows the tip of the laser fiber as a green aiming beam, which was used to target the stone 
During follow-up, 3 months later, an additional ERCP revealed a large and functional pancreatic papillotomy, an irregular Wirsung until distal body, with two strictures, and the pancreatic stent was removed.

Pancreatography suggested two pancreatic head stenosis and one body stenosis. At the pancreatic isthmus there was a calculus with a median diameter of $10 \mathrm{~mm}$ (Figure 1). The patient underwent retrogradeendoscopic stone fragmentation with a holmium laser with the SpyGlass DS system (Table 1). A Visualization System (SGDS), using a single-operator four-way deflected 10-Fr Spy- Scope inserted through the 4.2-mm working channel was achieved. The tip of the laser fiber had a green aiming beam (brightening regulated), which was used to target the stone under direct vision (Figure 2). Therefore, with the probe tip 1-2 mm away from the stone, and under intermittent saline irrigation, laser bursts were delivered through the aqueous medium until stone fragmentation was deemed complete. To summarize, pancreatoscopy-guided holmium laser, using a mini-endoscope inserted into the pancreatic duct successfully broken the impacted stone and cleared the obstruction, without complications. After successful treatment of the stone in 1 session, the stricture was further submitted to an increased number of plastic stents. At the end of endotherapy the patient remained asymptomatic during follow-up (6 months) without any symptoms, without pancreatic stenosis, without further interventions, and with higher quality of life.

Table 1 Patient medical history with imaging exams results and subsequent treatment

\begin{tabular}{|l|l|l|}
\hline March 2017 & CT & $\begin{array}{l}\text { Demonstrated a thin gallbladder and chronic pancreatitis's signs with } \\
\text { impacted pancreatic intraductal stones. }\end{array}$ \\
\cline { 2 - 3 } & MRCP & $\begin{array}{l}\text { Showed abnormal pancreatic parenchyma, a mild Wirsung dilatation and } \\
\text { an unknow stenosis at head of pancreas. To clarify, an echo-endoscopy } \\
\text { illustrated a 10-mm stone associated and a focal narrowing in body-tail } \\
\text { transition. }\end{array}$ \\
\hline April 2017 & ERCP & Was carry out to introduce a pancreatic stent (10Fr, 12 cm). \\
\hline July 2017 & ERCP & $\begin{array}{l}\text { Revealed a large and functional pancreatic papillotomy and irregular } \\
\text { Wirsung until distal body, with two strictures, and the pancreatic stent was } \\
\text { removed }\end{array}$ \\
\hline $\begin{array}{l}\text { September } \\
2017\end{array}$ & Pancreatography & $\begin{array}{l}\text { Suggested two pancreatic head stenosis and one body stenosis. Before } \\
\text { pancreatic istm there was a calculi with a median diameter of 10-mm. }\end{array}$ \\
\cline { 2 - 3 } & $\begin{array}{l}\text { Holmium } \\
\text { ERCP }\end{array}$ & $\begin{array}{l}\text { Mini endoscope inserted into the pancreatic duct successfully broken the } \\
\text { impacted stone and cleared the obstruction. }\end{array}$ \\
\hline March 2018 & Without any symptoms. \\
\hline
\end{tabular}

\section{Discussion}

We report a case of a patient with difficult pancreatic duct stones that could be treated with HL, which was a safe and effective treatment. It is a promising method for experienced gastroenterologists and can replace, in a near future external lithotripsy in the management of intraductal and pancreatic stones.

The technique enables a high-resolution imaging with a $60 \%$ wider field of view; a larger working channel (1.2 mm); a simplified procedure; a rescue therapy after failure of ESWL in endoscopic centers that have SpyGlass technology for bile duct/pancreas interventions available with success rates and transient complications.

However, few data are available [5], with high costs (but one-session treatment might be cost-effective) [3,6] and it's necessary to have centers that have the equipment and expertise on cholangioscopy and laser lithotripsy or EHL in CBD stones [3]. On other hand, there is no reported experience in Portugal with the second-generation digital cholangioscopy-guided lithotripsy system using HL. Development of single operator pancreatoscopy in contrast to conventional POP technology simplified POP procedure may lead to an increased use, mainly as a rescue therapy after failure of ESWL in endoscopic centers that have SpyGlass technology [3,6]. Fragmentation by holmium laser occurs primarily by a photothermal mechanism whereby there is direct transmittance of energy from the laser to the stone. This mechanism is fundamentally different from other laser lithotripsy modalities and depends on laser energy absorption of light with a longer wavelength of about $2100 \mathrm{~nm}$ on the surface of the stone as well as in the surrounding fluid. At the stone surface, melting and ejection of stone material occurs. This is then swept away by a vapor bubble that is created by water absorption of the laser energy. Because the holmium laser produces a high effective energy level, 
clear ductal vision is important to prevent inadvertent bile duct injury. When done under direct cholangioscopic or pancreatoscopic vision it has a good safety profile [7].

\section{Learning Points/Take Home Messages}

- $\quad$ Pancreatic duct stone formation is a chronic pancreatitis complication that causes recurrent episodes of pain and can be manage endoscopically.

- $\quad$ Patients with difficult pancreatic duct stones can be treated with holmium laser, which is a safe and effective treatment.

- Holmium Laser is a promising method for experienced gastroenterologists and may replace, in a near future external lithotripsy in the management of intraductal stones.

\section{Conclusion}

This method promotes disintegration and extraction of complex pancreatic calculi in one section and the possibility of management pancreatic calculi under direct vision, however, further studies should attempt to clarify the effectiveness in intrapancreatic duct stones.

\section{Compliance with ethical standards}

\section{Disclosure of conflict of interest}

No conflict of interest.

\section{Statement of informed consent}

Informed consent was obtained from all individual participants included in the study.

\section{References}

[1] Rosch T, Daniel S, Scholz M, Huibregtse K, Smits M, et al. (2002) Endoscopic treatment of chronic pancreatitis: a multicenter study of 1000 patients with long-term follow-up. Endoscopy. 34: 765-771.

[2] Ammann RW, Muench R, Otto R, Buehler H, Freiburghaus AU, et al. (1988) Evolution and regression of pancreatic calcification in chronic pancreatitis. A prospective long-term study of 107 patients. Gastroenterology 95: 10181028.

[3] Beyna T, Neuhaus H and Gerges C (2018) Endoscopic treatment of pancreatic duct stones under direct vision: Revolution or resignation? Systematic review. Dig Endosc. 30: 29-37.

[4] Tandan M and Nageshwar RD (2013) Endotherapy in chronic pancreatitis. World J. Gastroenterology. 19: 61566164.

[5] Maydeo A, Kwek BE, Bhandari S, Bapat M and Dhir V (2011) Single operator cholangioscopy-guided laser lithotripsy in patients with difficult biliary and pancreatic ductal stones. Gastrointest Endosc. 74: 1308-1314.

[6] Ito K, Igarashi Y, Okano N, Mimura T, Kishimoto Y, et al. (2014) Efficacy of combined endoscopic lithotomy and extracorporeal shock wave litho- tripsy, and additional electrohydraulic lithotripsy using the SpyGlass direct visualization system or X-ray guided EHL as needed, for pancreatic lithiasis. Biomed Res Int. 732-781.

[7] Canena J, Lopes L, Fernandes J, Alexandrino G, Lourenço L, et al. (2018) Outcomes of Single-Operator Cholangioscopy-Guided Lithotripsy in Patients with Difficult Biliary and Pancreatic Stones. GE Port J Gastroenterol 26: 105- 113. 